\title{
Comparative profiling of gossypol enantiomers and seed traits' related transcripts in cotton lines
}

\author{
Aron Michael Felts, Deependra Bhatta, Sarabjit Bhatti and Ahmad \\ Naseer Aziz* \\ Department of Agricultural and Environmental Sciences (DAES), Tennessee State University (TSU), 3500 John A. \\ Merritt Blvd., Nashville, TN, 37209-USA \\ *Corresponding author's email:aaziz@tnstate.edu \\ Citation \\ Aron Michael Felts, Deependra Bhatta, Sarabjit Bhatti and Ahmad Naseer Aziz. Comparative profiling of gossypol \\ enantiomers and seed traits' related transcripts in cotton lines. Pure and Applied Biology. Vol. 8, Issue 2, pp 1850- \\ 1860. http://dx.doi.org/10.19045/bspab.2019.80129
}

Received: 04/05/2019 Revised: 27/06/2019

Accepted: 28/06/2019

Online First: 29/06/2019

\section{Abstract}

Cotton (Gossypium spp.) is the world's third most important oilseed crop as well as an economic source of protein. However, the presence of (-)- gossypol limits the nutritional value of cottonseeds. To genetically profile relevant traits, seeds of the two cotton parental lines TM-1 ( $G$. hirstum) and 3-79 (G. barbadense) along with their 17 chromosomal substitution (CS) progenies were quantified for (-)- and (+)- enantiomer levels. The TM-1 parent was found to contain a higher ratio of (+)-:(-)- gossypol enantiomers (13.34:8.52 $\mu \mathrm{g} / \mathrm{mg})$ compared to that of 3-79 levels $(6.69: 7.41 \mu \mathrm{g} / \mathrm{mg})$ in the seeds. Among progeny CS-B (containing substituted chromosomes from $G$. barbadense in $G$. hirsutum background) lines, only CS-B17 was found to contain significantly lower $(7.65 \mu \mathrm{g} / \mathrm{mg})$ level of (+)-enantiomer in its seeds, and also had the lowest $(5.09 \mu \mathrm{g} / \mathrm{mg})$ amount of (-)- gossypol among all lines. A singular protocol was then devised for RNA yields from polysaccharide-rich cottonseeds of CS-B17 and its parents. Transcription derived fragments (TDFs) analyses of these three lines were conducted on seeds harvested at 28, 35 and 42 days post anthesis (DPA). 64 TDFs profiles were analyzed using differential expression analyses, and similarities were revealed between 3-79 and CS-B17 along with unique expression trends for CSB17. Such expression analyses, which are based on single chromosome differences with TM-1 parent while reflecting seed nutritional merit of 3-79 parent, may facilitate cotton breeding endeavors.

Keywords: Chromosome substituted lines; Cotton; High performance liquid chromatography; Nutrition traits; RNA extraction; Transcription derived fragments

\section{Introduction}

Cotton (Gossypium spp.) is regarded as one of the world's most important fiber crops while also being the third most important oilseed crop. USA is the world's third largest producer of cotton after China and India and remains its largest exporter [1]. Cotton belongs to the Malvaceae family within the genus Gossypium and has 45 diploids and six allopolyploid species, among which four are cultivated while others are wild [2]. Two widely cultivated natural allopolyploids, $G$. 
hirsutum and $G$. barbadense, originated independently two million years ago by trans-oceanic hybridization of A- genome in Africa with that of D- genome in Mexico [3]. Secondary cotton products like oils and seedmeals are used as feed or food for animals and humans while others serve as source of mulch and biomass [4]. Cottonseed oil is also called "heart oil", as it is cholesterol free and has a high level of antioxidants (Vitamin E), which also increase its storage life in cooked food [5]. Cottonseed meal is a high source of protein and is available in most parts of the world at lower costs compared to soybean meal [6].

Cotton and related species have pigment glands located in stems, leaves, seeds, and flower buds that have a natural phenolic aldehyde called gossypol. The lysigenous pigment glands found on the surfaces of cotton organs and tissues are the storage organs for terpenoid aldehydes as well as gossypol, a predominantly yellow colored polyphenol $[7,8]$. It has been found that gossypol is an integral part of the plant's selfdefense mechanism against insect pests and possibly, some diseases $[9,10]$. Studies conducted at different thermodynamic conditions have revealed that gossypol has a very high boiling point of $177-183^{\circ} \mathrm{C}$, and heating of cottonseeds during oil extraction binds gossypol to proteins thus reducing protein availability in cottonseed meals [11]. Excessive consumption of cotton seeds by animals has been known to result in gossypol toxicosis. To eliminate the problem of toxicity, glandless cotton varieties were developed by completely removing gossypol producing glands. However, such varieties tended to be more susceptible to insects, pests and diseases and thus could not perform well commercially [8]. Gossypol exists in its two isomeric forms; (+)- gossypol which is less toxic, and (-)- gossypol which is more toxic [12]. Variable ratios of (+)- and (-)- gossypol have been observed among existing species of cotton [13]. The amount needed to cause toxicosis depends on several factors such as overall levels of gossypol in seeds, detoxifying efficiency of microbes of various species, and the ratios of (+)- vs. (-)gossypol's enantiomers $[14,15]$. Some $G$. barbadense varieties contain high $\mathrm{O}$ methylated gossypol derivatives favoring the existence of (-)- gossypol [16]. Seeds belonging to $G$. barbadense contain a slightly higher ratio of (-)- gossypol, but lower amounts of both enantiomers than $G$. hirsutum [13]. No comparative report is yet available on the expression profiles from these two highly grown cotton types as well as their progeny CS-B (containing substituted chromosomes from $G$. barbadense in $G$. hirsutum background) lines that are expected to retain either seed traits from both parents. Transcriptome or microarray analyses has been used in cotton to reveal the upregulated and down regulated transcripts during salt stress [17], fiber development [18, 19], disease condition [20] and seed developmental stages $[21,22]$. RNA quality and integrity is important in molecular analyses, such as RT-PCR, cDNA library construction, northern blotting and RNA sequencing applications. The use of ordinary kits for RNA extraction from plant tissues containing high concentration of polysaccharides, phenolic compounds and other metabolites is not an appropriate approach especially when obtaining high quality RNA from immature cottonseeds is desired. RNA extraction from cotton plants is usually recommended through the use of cetyl-trimethyl-ammonium-bromide

(CTAB) method with some modifications $[22,23]$.

Here, we report comparison of cottonseeds from chromosomal substitution (CS) lines as well as their two parental lines (TM-1 and 379) for total gossypol contents while separating (+)- and (-)- forms, through high performance liquid chromatography (HPLC). 
For subsequent comparative expression profiling, a modified CTAB extraction protocol was devised to yield high quality total RNAs from cottonseeds harvested at different days post-anthesis (DPA).

Materials and methods

\section{Plant materials and growth}

Two parental lines [TM-1 (G. hirsutum) and 3-79 (G. barbadense)] along with their 17 chromosomal substitution progeny (CS-B) lines [24, 25] were obtained from Dr. Sukumar Saha (Crop Science Research Laboratory, United States Department of Agriculture-Agriculture Research Service, USA). Three plants of each were grown in a glass greenhouse at $24^{\circ} \mathrm{C}$ to $28^{\circ} \mathrm{C}$ using standard nursery gallons (4.5-liters) containers with Miracle-Gro potting mix (Scott Co., Marysville, OH). Plants were watered as needed and fertilized $(0.21 \mathrm{mg} \mathrm{N}$, $0.07 \mathrm{mg} \mathrm{P}$ and $0.14 \mathrm{mg} \mathrm{K}$ per Liter) bimonthly. Yellow pest strips (BASF Corporation, Suffolk, VA) as well as Natria Insecticidal Soap (Bayer CropScience AG, Cary, NC,), and Kontos (OHP Inc., Mainland, PA) were used for white fly control as per manufacturers' formulations. Cotton lines to be analyzed for RNA profiles were labeled with different color tags on first appearance of flowers to track their DPA before subsequently harvesting the seeds.

\section{Sample preparation for gossypol analysis}

Seed preparation for HPLC analyses was conducted using a modified procedure of Scheffler and Romano [10]. For wet dehulling, 20 seeds per sample were placed in $50 \mathrm{ml}$ centrifuge tubes containing $20 \mathrm{ml}$ of water at room temperature (below $40^{\circ} \mathrm{C}$ ); these tubes were then incubated at $27^{\circ} \mathrm{C}$ for 16 to $24 \mathrm{~h}$. After the seeds were imbibed, the rounded ends were compressed by hand to extrude the kernel from the hull and were stored separately at $-80^{\circ} \mathrm{C}$ till analysis. The frozen hulls and dehulled seeds were ground to a fine powder using mortar and pestle and the powdered samples were then transferred to $50 \mathrm{ml}$ centrifuge tubes. For the drying process, the tubes containing the samples were uncapped and placed in a pre-chilled freeze dryer (Freezone 7806021, Labconco, Kansas City, MO) for two days at $-20^{\circ} \mathrm{C}$. Freeze dried samples were then stored at $20^{\circ} \mathrm{C}$ until analyzed for gossypol contents.

\section{Sample preparation for profile analysis}

The developing cotton bolls were harvested at 28, 35 and 42 DPA, covering the seed development phase which is reported for high proteins and oil profiles in cotton [26]. A minimum of five samples from each of the cotton lines being analyzed for RNA profiles was harvested. Cotton fiber was manually removed from the seeds at 35 and 42 DPA (Figure 1) using forceps before storing at $-80^{\circ} \mathrm{C}$. RNA extraction was conducted with a modified CTAB extraction protocol to yield high quality total RNAs from cottonseeds harvested at different days post-anthesis (DPA) for subsequent comparative expression profiling, as described in section 2.5 .

\section{HPLC analysis}

Seeds from 19 cotton lines were further processed as per the AOCS recommended modified method of Hron et al. [7]. Freeze dried ground samples $(0.2 \mathrm{~g})$ were placed into $20 \times 125 \mathrm{~mm}$ tubes. Each tube containing the sample was then combined with $4 \mathrm{ml}$ of complexing reagent [2\% (R)-(-)-2-amino-1propanol, $10 \%$ glacial acetic acid, and $88 \%$ $\mathrm{N}, \mathrm{N}$ dimethylformamide] and heated at 95$100^{\circ} \mathrm{C}$ for $30 \mathrm{~min}$. After cooling for 30 minutes at room temperature, $16 \mathrm{~mL}$ of mobile phase [78:22 (v/v) acetonitrile $/ 10 \mathrm{mM}$ KH2PO4 buffer ( $\mathrm{pH}$ 3.0)] was added, and tubes were inverted 30 times to mix thoroughly. Three $\mathrm{ml}$ of the mixture was filtered using a syringe fitted with a 0.45 Whatman \#2 filter. Subsequently, $0.8 \mathrm{~mL}$ of each sample was further combined with an additional $0.8 \mathrm{~mL}$ mobile phase and analyzed immediately on HPLC (HP 1100 series, Hewlett Packard, Germany) fitted with an 
SGE Inertsil ODS-2 (Varian, Lake Forest, CA) reverse phase column $(5 \mu \mathrm{m}, 100 \mathrm{~mm} x$ $4.0 \mathrm{~mm}$ internal diameter) and a diode array detector set at $254 \mathrm{~nm}$. Mobile phase flow rate was set at $1 \mathrm{ml} / \mathrm{min}$, and sample injection volume was set at $20 \mu \mathrm{l}$ for the continuous operation of the HPLC instrument. Standard (+)- and (-)- gossypols-amine propanol isomers ([ \pm$]$-Gossypol from cotton seeds, Millipore Sigma, St. Louis, MO, USA) were also analyzed as per Horn et al. [7] to obtain individual peak areas (Figure 2) vs. mg values using linear regression. Three samples from each cotton line were analyzed independently by HPLC and quantification results were verified through SPSS (IBM Corporation, Armonk, NY) based analyses of variance.

\section{Total RNA extraction}

The modified CTAB [22, 23] method was further amended to be combined with PicoPure $^{\mathrm{TM}}$ RNA Isolation Kit (MDS Analytical Technologies, Sunnyvale, CA) procedure. All labware used for RNA extraction were pre-washed with $0.1 \%(\mathrm{v} / \mathrm{v})$ diethyl pyro-carbonate (DEPC) treated water while mortars and pestles were baked overnight at $140^{\circ} \mathrm{C}$ before use. Cottonseeds (100 mg) were crushed into fine powder under liquid nitrogen and were transferred to tubes containing $500 \mu \mathrm{l}$ extraction buffer [2\% CTAB, 2\% PVP (polyvinylpyrrolidone), 20 mM EDTA (pH 8.0), $1.4 \mathrm{M} \mathrm{NaCl}, 100 \mathrm{mM}$ Tris $\mathrm{HCl}(\mathrm{pH} \quad 8.0)$ and $2 \%$ betamercaptoethanol. Samples were then homogenized by a pellet mixer (VWR International, Radnor, PA) and incubated in a $65^{\circ} \mathrm{C}$ water bath for 10 minutes with inversions at every three minutes. Following the wet incubation, $500 \mu \mathrm{l}$ of phenol: chloroform $(25: 24)$ mixture was added to each sample tube which was vortexed for 15 seconds and incubated for five minutes at room temperature. These crude RNA samples were then centrifuged at 10,000 $\mathrm{g}$ for five minutes. The resulting upper phase was collected and an equal volume of chloroform: isoamylalcohol (24:1) mixture was added for incubation at room temperature for five minutes. After centrifugation at $10,000 \mathrm{~g}$ for 10 minutes, an equal volume of $5 \mathrm{M}$ ammonium acetate was added to the resulting supernatant. Each sample was then incubated at $-20^{\circ} \mathrm{C}$ for two hours before being centrifuged at $14,000 \mathrm{~g}$ for 20 minutes. RNA was eluted from the pellet by adding $20 \mu \mathrm{l}$ of PicoPure $^{\mathrm{TM}}$ buffer (MDS Analytical Technologies) as per manufacturer's protocol. Total RNA was quantified from the samples using Nanodrop Spectrometer ND1000 (Thermo Scientific, Wilmington, DE) to detect absorption at $260 \mathrm{~nm}$ and $280 \mathrm{~nm}$. RNA samples $(10 \mu \mathrm{l})$ were combined with 40X gel red (Biotium Inc. Fremont, CA) before loading onto $1 \%$ agarose gel electrophoresis ( $80 \mathrm{~V}$ for 45 minutes) and viewed under UV (320 nm) transilluminator.

\section{Reverse transcription (RT) and differential display analysis}

The RNA spectra ${ }^{\text {TM }}$ Kit (GenHunter Corporation, Nashville, TN) was used for reverse transcription (RT) of mRNAs, from cottonseed samples, using three anchored primers: $\mathrm{H}-\mathrm{T}_{11} \mathrm{~A}, \mathrm{H}-\mathrm{T}_{11} \mathrm{C}$ and $\mathrm{H}-\mathrm{T}_{11} \mathrm{G}$ to amplify RT products as per manufacturer's protocol. After adding the corresponding RH-T ${ }_{11} \mathrm{M}(\mathrm{M}=\mathrm{A}, \mathrm{C}$ or $\mathrm{G})$ reverse anchor primers, each of the three RT-reactions received eight arbitrary primers: $\mathrm{H}-\mathrm{AP} 1, \mathrm{H}-$ AP2, H-AP3, H-AP4, H-AP5, H-AP6, HAP7 and H-AP8, for 24 subsequent PCR amplifications. Each amplified DNA fragment was resolved through electrophoresis on $6 \%$ polyacrylamide gels, which were later scored (Figure 3). The DNA products were amplified from RNA TDFs, thus their relative intensities reflected corresponding expression levels. For the comparative scoring strength of DNA, bands was assessed and thereby brighter intensities were given higher values. Thus intensity of 
each TDF was quantified, using a given score of 0-26, by ImageJ software [27].

\section{Results and discussion}

\section{Gossypol enantiomer profiles}

Confirming earlier reports [11, 28], the analysis of seed samples of G. hirsutum (TM1) exhibited a higher percentage of (+)gossypol (13.34 $\mu \mathrm{g} / \mathrm{mg})$ than the (-)enantiomer $(8.52 \mu \mathrm{g} / \mathrm{mg})$ compared to that of G. barbadense $(6.69$ and $7.41 \mu \mathrm{g} / \mathrm{mg}$, respectively). Due to the higher toxicity of the (-)- gossypol enantiomer, higher levels of (+)- compared to (-)- forms are desired in cottonseed samples. This is the first report on HPLC profiling of (+)- and (-)- gossypol enantiomers of CS-B progeny lines with $G$. hirsutum background and G. barbadense foreground. Per Duncan Multiple Range Test (SPSS) of parental and progeny cotton lines' profiles, these were grouped based on separate analyses on both enantiomers' levels (Table 1). Six progeny lines, i.e., CS-B02, CS-B14sh, CS-B16, CS-B17, CS-B22lo, and CS-B25 had lower overall gossypol levels, especially that of the (-)-enantiomer. Also, three progeny lines, i.e., CS-B11sh, CSB12sh, and CS-B22lo had favorable variation of gossypol enantiomers [higher (+)- with lower (-)- enantiomer levels] warranting further analyses. CS-B17 had the lowest content of (-)- gossypol in seeds (5.09 $\mu \mathrm{g} / \mathrm{mg}$ ), and CS-B04 revealed the have the highest level (12.25 $\mu \mathrm{g} / \mathrm{mg})$ among all progeny lines. For (+)- gossypol levels, CSB17 seeds also showed the lowest value among the progeny lines while CS-B07 had the highest. Therefore, CS-B17 was found to have least total gossypol contents (12.75 $\mu \mathrm{g} / \mathrm{mg}$ ) in seeds and was thereby selected for TDF analyses along with its parental lines. Other progeny CS-B lines identified in this study may also be of interest for future analyses, when desirable level of (+)enantiomer in breeding stock is sought for insect resistance while reducing or eliminating the (-)- enantiomer contents in the seeds.

\section{Standardization of RNA extraction}

Cottonseeds are very high in polysaccharides, therefore a modified CTAB based protocol [22, 23] combined with PicoPure $^{\mathrm{TM}}$ kit (MDS Analytical Technologies) was required for extracting high quality RNA for expression profiling. CTAB solution was supplemented with $2 \%$ Polyvinylpyrrolidone (PVP) for dissolving membranes, inactivating ribonucleases, disrupting protein-nucleic acid interactions while removing polysaccharides, polyphenols and other secondary metabolites [29]. At $65^{\circ} \mathrm{C}, \mathrm{CTAB}$ reagent induced binding with polysaccharides (inhibits PCR amplifications), whereas phenolic compounds (powerful oxidizing agents covalently bonding with nucleic acids) were inactivated (forming hydrogen bonds) by PVP together with the extraction buffer. Addition of salt in the extraction buffer prevented bonding between polysaccharides and CTAB-RNA complexes and favored the removal of polysaccharides and $\mathrm{CTAB}$ during chloroform extraction [30].

Positive ions $\left(\mathrm{Na}^{+}\right)$in salt neutralized the negative charges of phosphates in the nucleic acids, allowing these to compact during extraction while beta-mercaptoethanol (added just before use), a strong reducing agent, helped to denature RNases and cleaned tannins and other polyphenols. The total RNA yields were further purified using PicoPure $^{\mathrm{TM}}$ RNA Isolation Kit (MDS Analytical Technologies) and treated with DNase I (OPTIZYME ${ }^{\mathrm{TM}}$, Fisher Scientific, Waltham, MA) to remove the traces of DNA. The resulting RNAs were of good quality with A260/A280 and A260/A230 ratios of 2.12-2.14 and 2.27-2.34 respectively (Table 2). The high percentage of RNA as indicated by UV260 absorption readings of samples along with low A280 and A230 values showed that contaminating proteins as well 
as polysaccharides and polyphenol compounds were diminished. However, the
28 DPA samples of TM-1 didn't yield any quantifiable RNA after extraction.

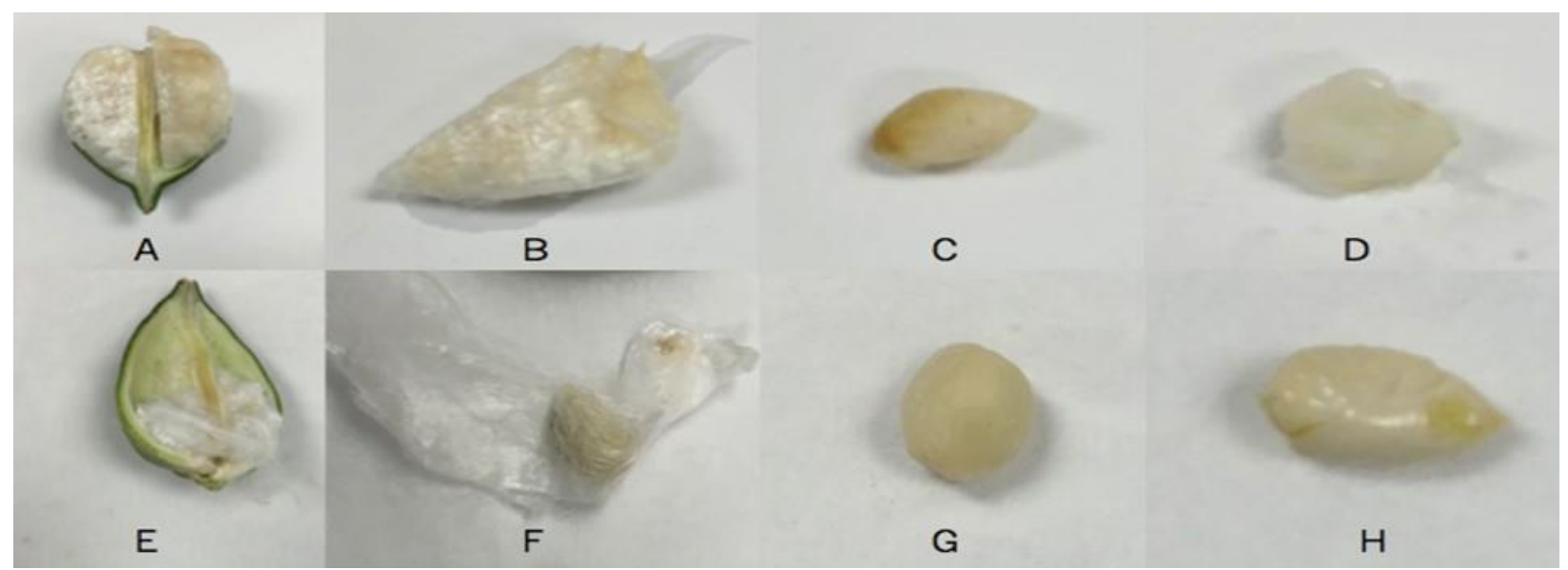

Figure 1. Seed Development Appearance at 35 and 42 days post anthesis (DPA) displaying cotton seeds stages of fiber, linter and hull removal: (A) 35 DPA cotton boll cut in half; (B) 35 DPA cottonseed with fibers; (C) 35 DPA cottonseed without linter; (D) 35 DPA cottonseed kernel without hull; (E) 42 DPA cotton boll cut in half; (F) 42 DPA cottonseed with fibers; (G) 42 DPA cottonseed without linter and (H) 42 DPA cottonseed kernel without hull

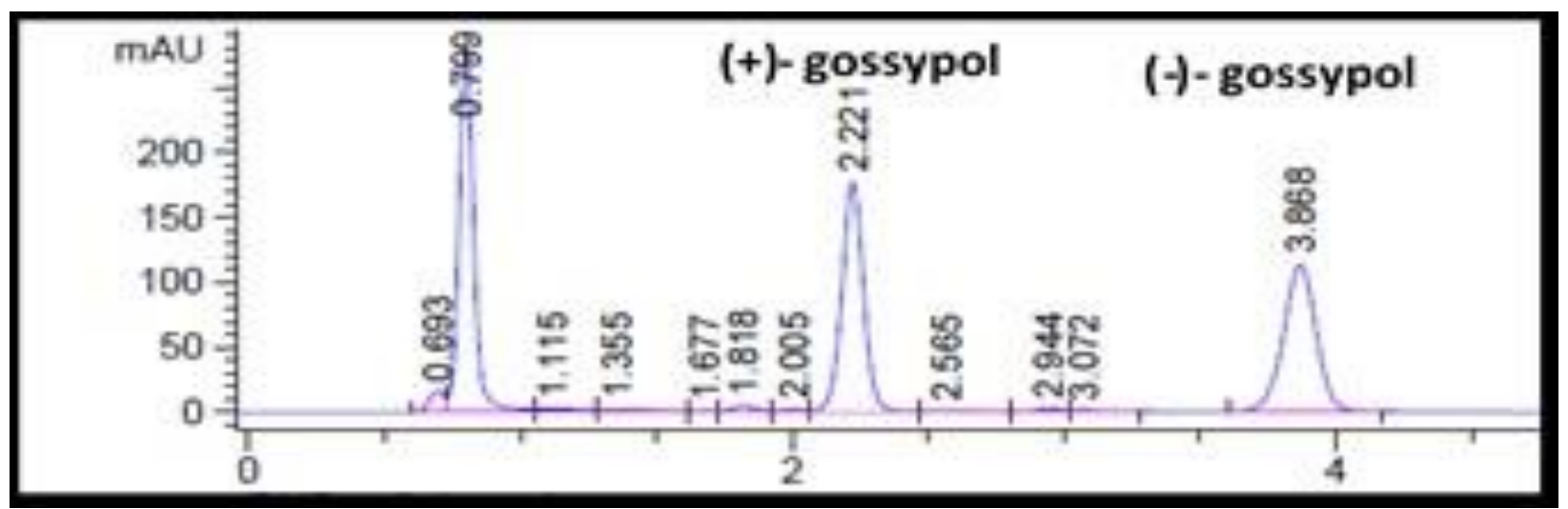

Figure 2. High Performance Liquid Chromatographic detection of (+)- and (-)- gossypol amine propanol isomers at two minutes 12 seconds and three minutes 48 seconds, respectively

Expressed cottonseed's DNA fragment at different developmental stages

The comparative expression analyses for the three selected cotton lines were conducted at the three seed developmental stages $(28,35$ and 42 DPA) using the intensities of the relevant amplified cDNA based bands through the differential display gels (Figure 3). The 24 primer combinations (GenHunter) provided discernible DNA profiles from each seed samples. From these profiles, 64 TDFs were selected for comparatively scoring their intensities ranging from 0-26 (Table 3). Six TDF trends were observed from 28 through 35 and to 42 DPA for CS-B17 that warrant further investigation. Trend 1, the most common trend, displayed a flat line from 28 to 35 DPA which then had increased expression at 42 DPA (observed for 16 TDFs). The next most frequent trend (Trend 
2) was observed for $10 \mathrm{TDFs}$, where downregulation from 28 DPA to $35 \mathrm{DPA}$ was displayed which then increased towards 42 DPA. Trend 3 was observed for nine TDFs, which displayed down-regulation from 28 DPA to 35 DPA that flattened off toward 42 DPA. Trend 41 TDFs (observed in 2) had increased intensity from 28 to 35 DPA which then flattened towards 42 DPA. Trend 5 TDFs (observed in 2) showed continuously increasing band intensity from 28 through 35 , and to 42 DPA. Lastly two TDFs showed upregulation from 28 DPA to 35 DPA but then had down-regulation from 35 DPA to 42 DPA (Trend 6). Fifteen of the 64 differentially expressed TDFs of CS-B17 displayed a band intensity either higher or lower than that of either parent. CS-B17 has been previously shown to be high in protein and oil traits when compared to both parents [31]. These findings may suggest similar expression patterns for those traits. While comparing the TDFs from cottonseeds at 35 DPA for CS-B17, 3-79 and TM-1, six were found to have the band intensity in-between that of TM-1 and 3-79. However, through 26 TDFs comparisons at 35 DPA, CS-B17 showed same band intensity as of 3-79 while only 10 TDFs were found similar to that of TM-1 parent. When comparing TDF trends at 42 DPA for CS-B17 and 3-79, 37 were commonly found to be up-regulated while the other eight were down-regulated. In similar comparison for CS-B17 and TM-1, only 20 TDFs were commonly found to be upregulated, while other five were downregulated. Thus, cottonseeds of CS-B17 at 35 and 42 DPA had a higher number of TDFs reflecting band intensity of 3-79 compared to that of TM-1, suggesting similar cellular activities in its seeds with that parent.

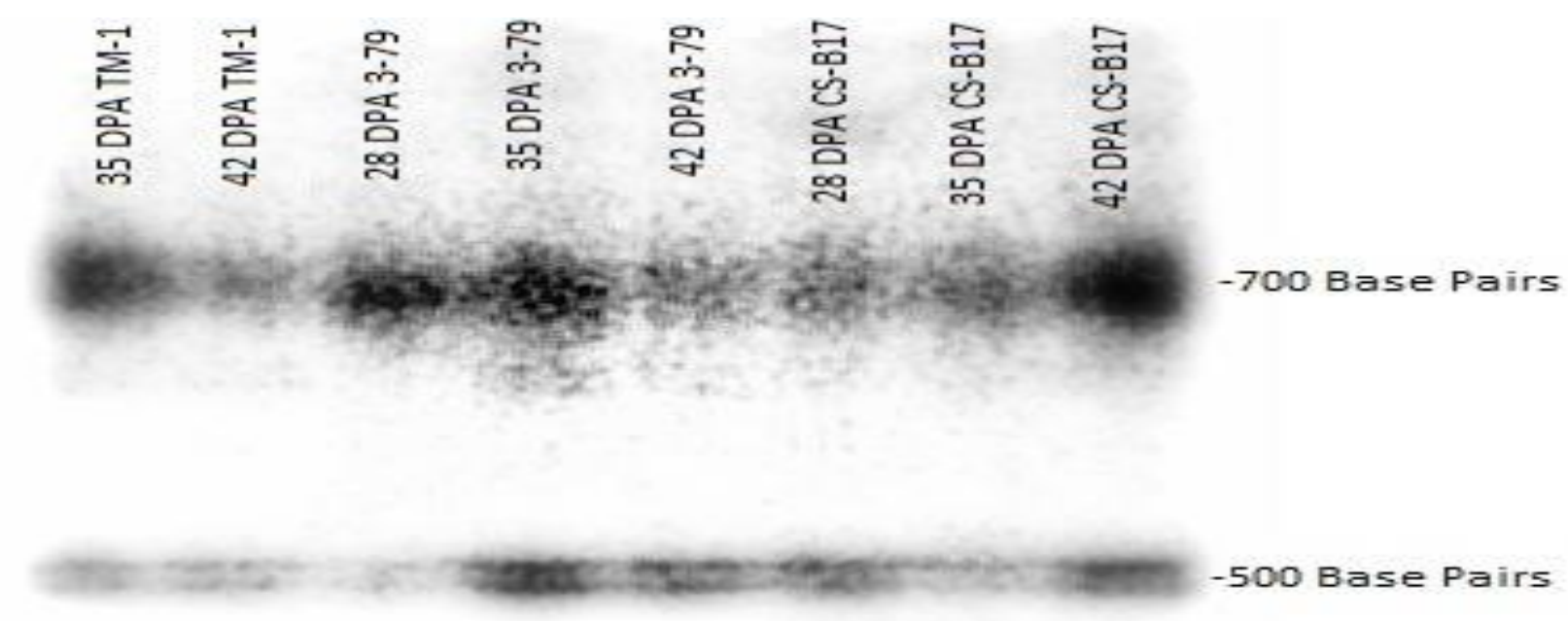

Figure 3. Two transcriptional derived fragments (TDFs) resolved on $6 \%$ polyacrylamide gel

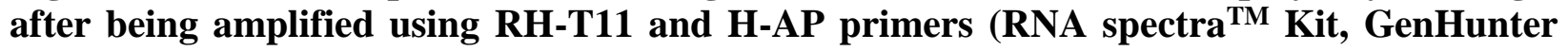
Corporation, Nashville, TN) using RNA samples from TM-1, 3-79, and CS-B17 cotton seed samples harvested at 28-, 35- and 42-days post anthesis (DPA) 
Table 1. Quantified levels of gossypol (+)- and (-)- enantiomers of cottonseeds from TM-1, 379, and their $17 \mathrm{CS}-\mathrm{B}^{\mathrm{z}}$ progeny lines through high performance liquid chromatographically (HPLC)

\begin{tabular}{|c|c|c|c|c|}
\hline Genotype & $\begin{array}{c}\text { (+)- isomer levels } \\
(\mu \mathrm{g} / \mathrm{mg})^{\mathrm{y}}\end{array}$ & $\begin{array}{c}\begin{array}{c}(-) \text { - isomer levels } \\
(\mu \mathrm{g} / \mathrm{mg})^{\mathrm{y}}\end{array} \\
\end{array}$ & $\begin{array}{l}\text { Total gossypol } \\
\text { levels }(\mu \mathrm{g} / \mathrm{mg})^{\mathrm{y}}\end{array}$ & $\begin{array}{l}\text { (+)- gossypol } \\
\text { ratio in seed }\end{array}$ \\
\hline TM-1 & $13.34 \pm 0.354^{\mathrm{fg}}$ & $8.52 \pm 0.223^{\text {th }}$ & $21.86 \pm 0.574^{\mathrm{f}}$ & $61 \%$ \\
\hline $3-79$ & $6.69 \pm 0.128^{a}$ & $7.41 \pm 0.112^{\text {cde }}$ & $14.11 \pm 0.236^{\mathrm{a}}$ & $47.50 \%$ \\
\hline CS-B01 & $13.87 \pm 0.133^{\mathrm{fgh}}$ & $8.82 \pm 0.103^{\text {hi }}$ & $22.7 \pm 0.210^{\mathrm{fg}}$ & $61.10 \%$ \\
\hline $\mathrm{CS}-\mathrm{B} 02$ & $10.5 \pm 1.189^{c d}$ & $7.17 \pm 0.804^{\text {cde }}$ & $17.67 \pm 1.994^{\mathrm{bc}}$ & $59.40 \%$ \\
\hline CS-B04 & $14.58 \pm 0.335^{\mathrm{gh}}$ & $12.25 \pm 0.306^{j}$ & $26.83 \pm 0.639^{\mathrm{h}}$ & $54.40 \%$ \\
\hline CS-B05sh & $11.86 \pm 0.519^{\mathrm{de}}$ & $7.43 \pm 0.31^{\text {cde }}$ & $19.29 \pm 0.826^{\text {cde }}$ & $61.50 \%$ \\
\hline CS-B06 & $13.01 \pm 0.642^{\mathrm{ef}}$ & $8.65 \pm 0.417^{\text {fhi }}$ & $21.66 \pm 1.057^{\mathrm{f}}$ & $60.10 \%$ \\
\hline CS-B07 & $14.73 \pm 0.315^{\mathrm{h}}$ & $9.61 \pm 0.26^{\mathrm{i}}$ & $24.34 \pm 0.571^{\mathrm{g}}$ & $60.50 \%$ \\
\hline CS-B11sh & $12.57 \pm 0.927^{\mathrm{ef}}$ & $8.39 \pm 0.567^{\text {degh }}$ & $20.96 \pm 1.494^{\mathrm{ef}}$ & $60 \%$ \\
\hline CS-B12sh & $12.79 \pm 0.386^{\mathrm{ef}}$ & $7.78 \pm 0.248^{\mathrm{def}}$ & $20.57 \pm 0.634^{\mathrm{def}}$ & $62.20 \%$ \\
\hline CS-B14sh & $11.09 \pm 0.699^{\mathrm{cd}}$ & $5.18 \pm 3.701^{\mathrm{cde}}$ & $16.27 \pm 1.038^{\mathrm{bcd}}$ & $68.10 \%$ \\
\hline CS-B15sh & $13.98 \pm 0.917^{\text {fgh }}$ & $8.89 \pm 0.667^{\mathrm{hi}}$ & $22.87 \pm 1.584^{\mathrm{fg}}$ & $61.10 \%$ \\
\hline CS-B16 & $10.02 \pm 0.441^{\mathrm{c}}$ & $6.74 \pm 0.343^{\mathrm{bc}}$ & $16.76 \pm 0.784^{b}$ & $59.80 \%$ \\
\hline CS-B17 & $7.65 \pm 1.822^{\mathrm{ab}}$ & $5.09 \pm 1.353^{\mathrm{a}}$ & $12.75 \pm 2.561^{\mathrm{a}}$ & $60 \%$ \\
\hline CS-B18 & $11.29 \pm 0.932^{\mathrm{cd}}$ & $8.0 \pm 0.808^{\text {defh }}$ & $19.29 \pm 1.736^{\text {cde }}$ & $58.50 \%$ \\
\hline CS-B22lo & $8.64 \pm 0.265^{\mathrm{ef}}$ & $5.81 \pm 0.072^{\text {cde }}$ & $14.45 \pm 0.323^{\mathrm{a}}$ & $59.80 \%$ \\
\hline CS-B22sh & $13.15 \pm 0.429^{b}$ & $7.41 \pm 0.283^{\mathrm{ab}}$ & $20.57 \pm 0.711^{\text {def }}$ & $64 \%$ \\
\hline CS-B25 & $10.56 \pm 0.545^{\mathrm{cd}}$ & $6.71 \pm 0.348^{\mathrm{bc}}$ & $17.28 \pm 0.893^{\mathrm{bc}}$ & $61.10 \%$ \\
\hline CS-B26lo & $13.27 \pm 0.925^{\mathrm{fg}}$ & $8.78 \pm 0.715^{\text {fhi }}$ & $22.05 \pm 1.638^{f}$ & $60.20 \%$ \\
\hline
\end{tabular}

${ }^{\mathrm{z}}$ As per Saha et al. (2004) and Stelly et al. (2005).

${ }^{y}$ Per multiple range test by Duncan post-hoc analyses (SPSS, IBM Corporation, Armark, NY), the means within a column having a different letter are significantly different at $\mathrm{P}=0.05$.

${ }^{\mathrm{x}}(+)$ - isomer level $(\mu \mathrm{g} / \mathrm{mg}) \div$ total gossypol level $(\mu \mathrm{g} / \mathrm{mg})$ x 100 
Table 2. Nanodrop quantification and purity readings of RNA extracts from cottonseeds of TM-1, 3-79 and CS-B17 harvested at 28, 35, and 42 days post anthesis (DPA)

\begin{tabular}{|c|c|c|}
\hline Seed Sample & $\mathbf{A 2 6 0 / 2 8 0}^{\mathbf{z}}$ & $\mathbf{A 2 6 0 / 2 3 0}^{\mathbf{z}}$ \\
\hline TM-1 at 35 DPA & 2.14 & 2.34 \\
\hline TM-1 at 42 DPA & 2.13 & 2.32 \\
\hline 3-79 at 28 DPA & 2.13 & 2.3 \\
\hline 3-79 at 35 DPA & 2.13 & 2.29 \\
\hline 3-79 at 42 DPA & 2.13 & 2.27 \\
\hline CS-B17 at 28 DPA & 2.12 & 2.3 \\
\hline CS-B17 at 35 DPA & 2.14 & 2.33 \\
\hline CS-B17 at 42 DPA & 2.12 & 2.34 \\
\hline
\end{tabular}

${ }^{\mathrm{z}}$ Absorbance values reported after averaging readings from five separate samples analyzed at UV230, UV 260 and UV280

Table 3. 64 unique Transcription Derived Fragments (TDFs) were selected from RNA samples of TM-1, 3-79, and CS-B17 cottonseeds produced by three anchor primers and eight arbitrary primers

\begin{tabular}{|c|c|c|c|}
\hline Anchor Primer $^{\mathbf{z}}$ & $\begin{array}{c}\text { Arbitrary } \\
\text { Primers }^{\mathbf{z}}\end{array}$ & Scored TDFs & Intensity Range $^{\mathbf{y}}$ \\
\hline RH-T $_{11} \mathrm{~A}$ & H-AP1 & 3 & $0-18$ \\
\hline & H-AP2 & 7 & $0-18$ \\
\hline & H-AP3 & 8 & $0-18$ \\
\hline & H-AP4 & 6 & $0-19$ \\
\hline & H-AP5 & 2 & $0-13$ \\
\hline & H-AP6 & 8 & $0-14$ \\
\hline & H-AP7 & 3 & $0-26$ \\
\hline RH-T $_{11} \mathrm{C}$ & H-AP8 & 5 & $0-15$ \\
\hline & H-AP1 & 4 & $0-16$ \\
\hline & H-AP3 & 2 & $0-18$ \\
\hline & H-AP4 & 2 & $1-17$ \\
\hline & H-AP5 & 2 & $0-17$ \\
\hline & H-AP8 & 3 & $0-26$ \\
\hline RH-T $_{11} \mathrm{G}$ & H-AP1 & 1 & $1-14$ \\
\hline & H-AP2 & 1 & $0-14$ \\
\hline & H-AP3 & 3 & $1-14$ \\
\hline & H-AP4 & 3 & $0-16$ \\
\hline & H-AP5 & 1 & $0-11$ \\
\hline
\end{tabular}

${ }^{2}$ The three anchor primers and eight arbitrary primers of RNA Spectre ${ }^{\mathrm{TM}}$ kit (GenHunter Corporation, Nashville, TN) produced over $100 \mathrm{TDFs}$ from each of the three cottonseed samples analyzed.

${ }^{y}$ The relative intensities (zero to 26) of the selected TDFs were assigned by the ImageJ software (Rasband, 2016)

\section{Conclusion}

Though G. barbadense has higher O-methylated gossypol derivatives [16], it is reported with lower levels of (-)- gossypol compared to $G$. hirsutum [28] and thus may have desirable seed usage traits. CSB-17 expressed (+)-gossypol patterns comparable to that of $G$. barbadense parent while its (-)- enantiomer levels were also significantly lowest among all the lines. CS-B17 seeds have been found to contain high levels of protein and oil compared to both parents [31]. The TDF comparative profiling also indicates that this line may be harboring desirable nutritional traits from both parents. Further sequencing analyses on TDFs reported here, may reveal the genotypic associations of cottonseed 
traits for CS-B17 and 3-79 lines. Through HPLC analyses eight progeny lines (CS-B02, CSB11sh, CS-B12sh, CS-B14sh, CS-B16, CS-B17, CS-B22lo, and CS-B25) were identified for harboring desirable [higher in (+)- while lower in (-)-] gossypol enantiomer levels. However, CSB17 was analyzed by RT and differential display to further demonstrate that 3-79 genetic foreground may have bearing in its protein and oil relevant seed traits. This study can facilitate the selection of suitable cotton lines for breeding trials in improving seed traits for feed and/or food usages.

\section{Authors' contributions}

Conceived and designed the experiments: AN Aziz \& S Bhatti, Performed the experiments: A Felts \& D Bhatta, Analyzed the data: S Bhatti, A Felts, D Bhatta \& AN Aziz, Contributed materials/ analysis/ tools: AN Aziz, Wrote the paper: A Felts, D Bhatta, \& AN Aziz.

\section{Acknowledgements}

Dr. Sukumar Saha (USDA-ARS, Genetics and Sustainable Agriculture Research Unit, MS, 39762) for providing cotton lines' seeds. USDA/NIFA Evans-Allen Grant to TSU's College of Agriculture, Human and Natural Sciences.

\section{References}

1. Statista (2018). Cotton production by country worldwide in 2017/2018. https://www.statista.com/statistics/263055/c otton-production-worldwide-by-topcountries/.

2. Maleia MP, Filho PSV, Goncalves-Vidigal MC, Gonela A, Lacanallo GF, Moiana LD, Chamuene A, De Sousa LL \& Darben LM (2010). Genetic divergence among African and American cotton (Gossypium hirsutum L. race latifolium $\mathrm{H}$.) cultivars and inbred lines through random amplification of polymorphic DNA (RAPD) markers. Afr $J$ Biotechnol 9: 8539-8548.

3. Senchina DS, Alvarez I, Cronn RC, Liu B, Rong J, Noyes RD, Paterson AH, Wing RA, Wilkins TA \& Wendel JF (2003). Rate variation among nuclear genes and the age of polyploidy in Gossypium. Mol Biol Evol 20: 633-643.

4. Saha S, Stelly DM, Raska DA, Wu J, Jenkins JN, McCarty JC, Makamov A, Gotmare V,
Abdurakhmonov IY \& Campbell IY (2012). Chromosome substitution lines: Concept, development and utilization in the genetic improvement of upland cotton. In: Abdurakhmonov I, editor. Plant Breeding. London: InTech. pp. 107-128.

5. Ashokkumar K, \& Ravikesavan R (2008). Genetic studies of combining ability estimates for seed oil, seed protein and fiber quality traits in upland cotton $(G$. hirsutum L.). J Agr Biol Sci 4: 798-802.

6. Li MH, \& Robinson EH (2006). Use of cottonseed meal in aquatic animal diets: A Review. $N$ Am J Aquacult 68: 14-22.

7. Hron Sr RJ, Kim HL, Calhoun MC \& Fisher GS (1999). Determination of (+)- and (-)-, and total gossypol in cottonseed by HPLC. $J$ Am Oil Chem 76: 1351-1355.

8. Cai Y, Xie Y \& Liu J (2010). Glandless seed and glanded plant research in cotton. A review. Agron Sustain Dev 30: 181-190.

9. Bell AA, \& Stipanovic RD (1977). The chemical composition, biological activity, and genetics of pigment glands in cotton. In: Brown JM, editor. Proceedings of Beltwide cotton production research conference. Memphis: National Cotton Council of America. pp. 244-258.

10. Scheffler JA, \& Romano GB (2008). Breeding and genetics: Modifying gossypol in cotton (Gossypium hirsutum L.): A cost effective method for small seed samples. $J$ Cotton Sci 12: 202-209.

11. Mannann S, Shad MA \& Perveen A (2010). Detection of a toxic phenolic compound in cottonseed extract and its products. Pakistan J Nutr 9: 994-997.

12. Gadelha IC, Fonseca NB, Oloris SC, Melo MM \& Soto-Blanco B (2014). Gossypol toxicity from cottonseed products. Sci World J 2014: 231635.

13. Cass QB, Oliveira RV \& De Pietro AC (2004). Determination of gossypol enantiomer ratio in cotton plants by chiral higher-performance liquid chromatography. J Agr Food Chem 52: 5822-5827.

14. Robinson PH, Getachew G, De Peters EJ \& Calhoun MC (2001). Influence of variety and storage up to 22 days on nutrient composition and gossypol level of Pima 
cottonseed (Gossypium spp.). Anim Feed Sci Tech 91: 149-156.

15. Santos JEP, Villasenor M, Robinson PH, DePeters EJ \& Holmberg CA (2003). Type of cottonseed and level of gossypol in diets of lactating dairy cows: Plasma gossypol, health, and reproductive performance. $J$ Dairy Sci 86: 892-905.

16. Dowd MK, \& Pelitire SM (2008). HPLC preparation of the chiral forms of 6methoxy-gossypol and 6,6'-dimethoxygossypol. J Chromatogr B 867: 69-77.

17. Yao D, Zhang $X$, Zhao X, Liu C, Wang C, Zhang Z, Zhang C, Wei Q, Wang Q, Yan H, Li F \& Su Z (2011). Transcriptome analysis reveals salt-stress-regulated biological processes and key pathways in roots of cotton (Gossypium hirsutum L.). Genomics 98: 47-55.

18. Nigam D, Kavita P, Tripathi RK, Ranjan A, Goel R, Asif M, Shukla A, Singh G, Rana D \& Sawant SV (2014). Transcriptome dynamics during fiber development in contracting genotypes of Gossypium hirsutum L. Plant Biotechnol J 12: 204-218.

19. Gilbert MK, Turley RB, Kim HJ, Li P, Thyssen G, Tang Y, Delhom CD, Naoumkina M \& Fang DD (2013). Transcript profiling by microarray and marker analysis of the short cotton (Gossypium hirsutum L.) fiber mutant Ligon lintless-1 (Li 1). BMC Genomics 14: 403.

20. Zhang Y, Wang XF, Ding ZG, Ma Q, Zhang GR, Zhang SL, Li ZK, Wu LQ, Zhang GY, \& Ma ZY (2013). Transcriptome profiling of Gossypium barbadense inoculated with Verticillium dahliae provides a resource for cotton improvement. BMC Genomics 14: 637.

21. Hovav R, Faigenboim A, Kadmon N, Hu G, Zhang X, Gallagher JP \& Wendel JF (2015). A Transcriptome Profile for Developing Seed of Polyploid Cotton. Plant Genome 8: $1-15$.

22. Zhang $\mathrm{H}$, Wan Q, Ye W, Lv Y, Wu H \& Zhang T (2013). Genome wide analysis of small RNA and novel microRNA discovery during fiber and seed initial development in Gossypium hirsutum. L. Plos One 8(7): 1-9.

23. Zhao L, Ding Q, Zeng J, Wang FR, Zhang J, Fan SJ \& He XQ (2012). An improved CTAB-ammonium acetate method for total RNA isolation from cotton. Phytochem Analysis 23: 647-650.

24. Saha S, Wu J, Jenkins JN, McCarty Jr JC, Gutierrez OA, Stelly DM, Percy RG \& Raska DA (2004). Breeding and Genetics: Effect of chromosome substitutions from Gossypium barbadense L. 3-79 into $G$. hirsutum L. TM-1 on agronomic and fiber traits. J Cotton Sci 8: 162-169.

25. Stelly DM, Saha S, Raska DA, Jenkins JN, McCarty Jr JC \& Gutierrez O (2005). Registration of 17 Upland (Gossypium hirsutum) cotton germplasm lines disomic for different $G$. barbadense chromosome or arm substitutions. Crop Sci 45: 2663-2665.

26. Leffler HR (1986). Developmental Aspects of Planting Seed Quality. In: Brown JM, editor. Cotton Physiology. Memphis, TN: The Cotton Foundation Publisher. pp. 465474.

27. Rasband WS (1997-2018). ImageJ. U.S. National Institutes of Health. Bethesda, Maryland. https://imagej.nih.gov/ij/

28. Stipanovic RD, Puckhaber LS, Bell AA, Percival AE \& Jacobs J (2005). Occurrence of (+)- and (-)- gossypol in wild species of cotton and in Gossypium hirsutum Var. Marie-Galante (Watt) Hutchinson. J Agr Food Chem 53: 6266-6271.

29. Rezadoost MH, Kordrostami M \& Kumleh $\mathrm{HH}$ (2016). An efficient protocol for isolation of inhibitor-free nucleic acids even from recalcitrant plants. 3 Biotech 6: 61.

30. Wang L, \& Stegemann JP (2010). Extraction of high quality RNA from polysaccharide matrices using cetlytrimethylammonium bromide. Biomaterials 31: 1612-1618.

31. Wu J, Jenkins JN, MaCarty JC \& Thaxton P (2009). Seed trait evaluation of Gossypium barbadense $L$. chromosomes/arms in a $G$. hirsutum L. background. Euphytica 167: 371-380. 